\title{
CORRELATION BETWEEN LUMBAR LORDOSIS ANGLE AND DEGREE OF GYNOID LIPODYSTROPHY (CELLULITE) IN ASYMPTOMATIC WOMEN
}

\author{
Giovana Barbosa Milani, ${ }^{I}$ A’Dayr Natal Filho, ${ }^{I I}$ Sílvia Maria Amado João ${ }^{I}$
}

doi: $10.1590 / \mathbf{S 1 8 0 7 - 5 9 3 2 2 0 0 8 0 0 0 4 0 0 0 1 5}$

\begin{abstract}
Milani GB, A’Dayr NF, Amado João SM. Correlation between lumbar lordosis angle and degree of gynoid lipodystrophy (cellulite) in asymptomatic women. Clinics. 2008;63:503-8.
\end{abstract}

INTRODUCTION: Gynoid lipodystrophy (cellulite) has been cited as a common dermatological alteration. It occurs mainly in adult women and tends to gather around the thighs and buttocks. Its presence and severity have been related to many factors, including biotype, age, sex, circulatory changes, and, as some authors have suggested, mechanical alterations such as lumbar hyperlordosis.

OBJECTIVE: To correlate the degree of cellulite with the angle of lumbar lordosis in asymptomatic women.

METHODS: Fifty volunteers were evaluated by digital photos, palpation, and thermograph. The degree of cellulite was classified on a scale of 1-4. Analyses were performed on the superior, inferior, right and left buttocks (SRB, IRB, SLB, ILB), and the superior right and left thighs (SRT, SLT). The volunteers underwent a lateral-view X-ray, and the angle of lumbar lordosis was measured using Cobb's method (inferior endplate of T12 and the superior endplate of S). The data were statistically analyzed using ANOVA and Spearman's correlation. A significance level of 5\% was adopted.

RESULTS: Volunteers had a mean age of $26.1 \pm 4.4$ years and a mean body mass index of $20.7 \pm 1.9 \mathrm{~kg} / \mathrm{m}^{2}$. There was no significant difference in lumbar lordosis angle between those with cellulite classes 2 and 3 ( $p \geq 0.297)$. There was also no correlation between lumbar lordosis angle and the degree of cellulite ( $\mathrm{p} \geq 0.085$ and $r \geq 0.246$ ).

CONCLUSIONS: The analysis suggests that there is no correlation between the degree of cellulite and the angle of lumbar lordosis as measured using Cobb's method.

KEYWORDS: Cellulitis. Lordosis. Physical therapy. Evaluation. Radiography.

\section{INTRODUCTION}

Gynoid lipodystrophy (cellulite) has been cited as a very common dermatological occurrence in post-pubertal women. ${ }^{1-4}$ The skin acquires a padded look or an "orange peel" aspect on the affected areas. ${ }^{1}$ Approximately $85 \%$ of women in this age group have cellulite, ${ }^{1,5}$ which can be considered a normal aspect in mature women, ${ }^{3,5}$ and not a pathology as it has been called by some authors. ${ }^{3-6}$

\footnotetext{
I Musculoskeletal Assessment Laboratory, Department of Physical Therapy, Speech and Occupational Therapy - Faculdade de Medicina da Universidade de São Paulo - São Paulo/SP, Brazil.

II Orthopedic Department - Hospital Universitário da Universidade de São Paulo - São Paulo/SP, Brazil.

Email: gio.milani@usp.br

Received for publication on March 04, 2008

Accepted for publication on May 29, 2008
}

The term "cellulitis" has been used in the scientific literature in English to identify a spreading gangrenous infection in the subcutaneous cellular tissue, ${ }^{7}$ however, other denominations such as adiposis edematosa,${ }^{3}$ lipodystrophy, ${ }^{7}$ edematofibrosclerotic panniculitis ${ }^{7}$ and liposclerosis, ${ }^{7}$ have also been used. These terms differ from each other with respect to pathogenesis and morphology ${ }^{7}$. Rossi and Vergnanini ${ }^{8}$ explained that due to this plurality of names, several authors prefer to use the term cellulite.

Despite the high incidence of cellulite, there is no consensus on the origin and the basic aspects of its histopathological classification. ${ }^{7}$ According to Terranova et $\mathrm{al},{ }^{7}$ there are three main hypotheses concerning the ethiopathogenesis of cellulite. According to one theory, cellulite is involves an edema in the conjunctive tissue that accumulates a significant amount of water and is caused 
primarily by the accumulation of proteoglycans in the extracellular matrix. ${ }^{5,9}$ These authors suggest that greater tissue hydrophilia leads to a chronic edema that may result in fibrosis.

A second hypothesis attributes cellulite to microcirculatory alterations involving compression of the venous and lymphatic systems. ${ }^{1,2,6}$ According to Terranova et al., ${ }^{7}$ this circulatory alteration is related to adiposity, since histological examination during the initial stage of cellulite development revealed adipocytes with different forms and sizes associated with edema and dilation of the lymphatic vessels. Rossi and Vergnanini ${ }^{8}$ also reported that blood flow in the celluliteaffected areas was 35\% lower than in unaffected areas.

A third hypothesis focuses on the peculiarities of the female subcutaneous tissue., ${ }^{2,5,6,10,11}$ The adipose areolar layer is organized in interlobular septae of conjunctive tissue, ${ }^{1,12}$ which presents perpendicular projections in women and oblique projections in men, a difference that may determine or differentiate the appearance of cellulite in the two genders. ${ }^{6,11,12}$

Fink et al. ${ }^{13}$ defended yet another hypothesis, which attributes cellulite occurs to herniation of adipose tissue; this herniation is associated with loss of collagen integrity in the affected region.

A detailed clinical assessment ${ }^{8,14}$ and a complete anamnesis including daily habits ${ }^{8,14}$ are required in order to evaluate cellulite and also to establish the presence of factors that can influence cellulite appearance, including the following: hormonal contraceptives, ${ }^{5,14}$ stress, ${ }^{5,8}$ sedentary lifestyle, ${ }^{5,8}$ obesity, ${ }^{5,6,14}$ heredity, ${ }^{6,8}$ age, ${ }^{6}$ sex, ${ }^{6,8,15}$ hormonal dysfunction, ${ }^{8,14,15}$ tabagism,${ }^{8}$ pregnancy, ${ }^{8}$ excessive intake of coffee and alcohol, ${ }^{8,14}$ inadequate nutrition, ${ }^{8,15}$ circulatory changes ${ }^{8,15}$ and mechanical factors. ${ }^{14}$

Sandoval ${ }^{14}$ concluded that the following are mechanical factors that can affect cellulite appearance: orthostatic alterations, such as flat-footedness; and lumbar spine alterations, such as hyperlordosis. In addition, Piérard and Quatresooz ${ }^{10}$ reported that in the areas where cellulite was evident, the appearance of the skin changed as a function of the position of the lower limb. Therefore, the authors concluded that body postures tend to compress the adipose tissue in specific areas, thereby enhancing the "skin dimpling" in those areas.

Since cellulite appears mainly in the buttocks and posterior thigh areas, ${ }^{3,5,9}$ changes in the in the curvature of lumbar spine may interfere with the local blood supply, influencing the appearance and degree of cellulite. Therefore, the goals of this study were to compare groups with different degrees of cellulite and different angles of lumbar lordosis, and to assess whether a correlation exists between the lumbar lordosis angle and the degree of cellulite.

\section{MATERIALS AND METHODS}

\section{Sample}

Fifty female volunteers participated in this prospective study: they were students at a local university and their ages ranged from 20 to 35 years. The women included in this study were asymptomatic, i.e., had no symptoms of neurological, breathing, circulatory or rheumatic diseases. Volunteers filled out an anamnesis and record of daily habits, and the following criteria were used to exclude subjects: sedentary lifestyle; ${ }^{16}$ current or previous pregnancy; obesity or body mass index (BMI) greater than or equal to 24.9 $\mathrm{kg} / \mathrm{m} ;{ }^{2}$ previous surgeries related to posture; and lower back pain that has caused some level of incapacity. Subjects received a full explanation regarding the aims of the study and signed a written consent statement previously approved by the Ethical Committee of the Universitary Hospital of University of Sao Paulo.

Physical activity level was assessed using the shorter version of the International Physical Activity Questionnaire in order to classify the subjects into five categories: very active, for those performing vigorous activities $\geq 5$ days/week for $\geq 30$ minutes per session; active, for those performing vigorous activities $\geq 3$ days/week and $\geq 20$ minutes per session); irregularly active, for those not meeting the criteria of "active" or "very active"; irregularly active A, for those performing physical activity at a frequency of 5 days/week or a duration of 150 minutes/week; irregularly active B, for those failing to meet any of the criteria for "active" or "irregularly active A"; and sedentary, for those who did not perform any physical activity for at least 10 continuous minutes during the week. ${ }^{16}$

\section{Experimental Procedure}

For the body evaluation, volunteers were positioned in orthostatism on a wooden base $(19 \times 37 \times 44 \mathrm{~cm})$ and wore bathing suits. The waist-to-hip ratio was calculated using the waist measurement, which was measured at the narrowest point between the ribs and the iliac crest, and the hip measurement, which was characterized at the greatest protrusion of the buttocks. This ratio was also used to determine whether the fat distribution occurred in a central way (android) or in an inferior way (gynoid). ${ }^{17}$ Cellulite assessment and photographic registration of the posterior view were performed with and without gluteal muscle contraction. ${ }^{8}{ }^{818}$ A digital camera (Canon PowerShot A40, 2.0 megapixels) was positioned orthogonally at a distance of $1 \mathrm{~m}$ from the wooden base, and the camera lens was positioned based on the height of the sacrum of each volunteer. 
The assessed area was delimited using imaginary lines from the posterior superior iliac spine (PSIS) to the inferior gluteus-femoral sulcus, and from the greater trochanter to the inter-gluteus sulcus. A medial line between the PSIS and the gluteus-femoral sulcus was also established, dividing the buttocks area into right superior (RSB) and left superior buttock (LSB), and right (RIB) and left inferior buttock (LIB). In addition to these areas, the third proximal area of the thigh was also included and measured separately as the right superior thigh (RST) and left superior thigh (LST), with right and left defined from the subject's own point of view.

Next, the subjects were positioned in ventral decubitus to perform the palpation of the area under study area to verify the existence and size of the nodules. ${ }^{8}$ After 15 minutes of rest, the delimited areas were subjected to thermograph evaluation using a contact thermography plate with liquid crystals (Cellu-Test ${ }^{\circledR}$, Milano, Italy). The color of the plate changes according to the skin temperature. ${ }^{9}$ Based on guidelines from the International Products and Service, ${ }^{19}$ the outcome image was analyzed by considering the image uniformity, the presence of stains with no definite edges, the presence of clear or black stains, and the homogeneity of the colors. ${ }^{19}$ The mean weather temperature registered on the days of data acquisition was $18.7 \pm 3.7^{\circ} \mathrm{C}$; however, for the coldest days, heaters were used to keep the examination room at a temperature of approximately $20^{\circ} \mathrm{C}$.

Considering the data acquired using the techniques previously described (palpation, photography, and thermography), cellulite was classified into one of four levels, according to table 1 . $^{6,8}$

After the cellulite assessment, a standardized X-ray in the lateral view was taken of the lumbar spine including the $12^{\text {th }}$ thoracic vertebra (T12) and the $1^{\text {st }}$ sacral vertebra (S1). The subjects were placed in orthostatic position with their upper

Table 1 - Cellulite classification

Degree 1 Meaning asymptomatic or latent, with no clinical alterations

Degree 2 Alterations were visible only due to palpation or muscle contraction, and they included alterations to the circulatory system, absence of pain, and reduction in skin temperature and elasticity

Degree 3 When an "orange peel" appearance was visible upon simple inspection and alterations were similarly visible even without tissue compression, and the alterations became more apparent under compression, with these changes involving the presence of nodules during palpation and changes in the sensations of pain

Degree 4 Alterations could be observed in any position adopted by the subject, and these were large and painful nodules adhering to the deep tissues. In this last degree, the skin was flaccid and wrinkled, it presented a "nutshell" appearance. Fibrosis was a dominant characteristic, pain sensations were increased, and compromised nervous tissue could be present limbs at $90^{\circ}$ of flexion. The lumbar angles were measured using Cobb's method, which uses the angle formed between the lines at the level of the superior and inferior endplates of determined vertebrae. ${ }^{20-24}$ Therefore, the angle formed between the lines drawn at the level of the inferior endplate of T12 and the superior endplate of S1 was determined..$^{20-26}$ All the radiological parameters were performed by the same researcher $(\mathrm{GBM})$. The subjects were divided into groups based on lumbar lordosis angle ${ }^{27}$ measured using Cobb's method (Figure 1).

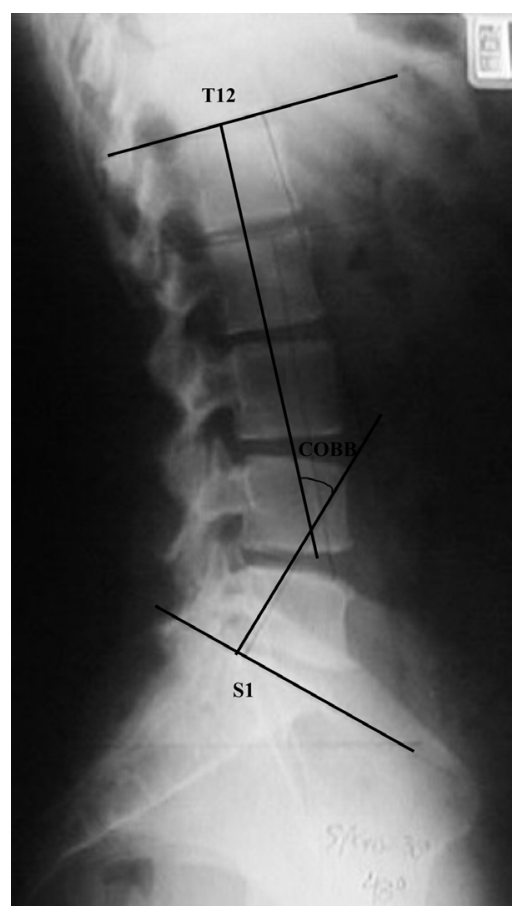

Figure 1 - Total lumbar lordosis angle determined by Cobb's method, using the intersection of lines at the level of the inferior plateau of T12 and the superior plateau of $\mathrm{S} 1$

\section{Statistical Analysis}

Statistical analyses were performed using Bioestat 4.0 software (Brazil). The data were tested for normal distribution using the Anderson-Darling test. The data for the angle of lumbar lordosis were normally distributed; therefore analysis of variance (ANOVA) was performed in order to observe differences among groups. The degree of cellulite was not normally distributed, so the non-parametric Spearman test was performed. The level of significance was set at $5 \%$.

\section{RESULTS}

Subjects had a mean age of $26.1 \pm 4.4$ years and a mean BMI of $20.7 \pm 1.9 \mathrm{~g} / \mathrm{m}^{2}$. The other characteristics considered but not analyzed in the present study are shown in Table 2 . 
Table 2 - Characterization of the participant cohort

\begin{tabular}{|c|c|}
\hline \multicolumn{2}{|l|}{ Skin type } \\
\hline White & $35(70 \%)$ \\
\hline Asian & $11(22 \%)$ \\
\hline Black & $4(8 \%)$ \\
\hline Mean waist-to-hip ratio (cm) & $0.73 \pm 0.04$ \\
\hline \multicolumn{2}{|l|}{ Level of physical activity } \\
\hline Very active & $4(8 \%)$ \\
\hline Active & $33(66 \%)$ \\
\hline Irregularly active $\mathrm{A}$ & $5(10 \%)$ \\
\hline Irregularly active $B$ & $8(16 \%)$ \\
\hline \multicolumn{2}{|l|}{ Hormonal disturbance } \\
\hline No & $43(86 \%)$ \\
\hline \multicolumn{2}{|l|}{ Contraceptive device } \\
\hline Pill & $23(46 \%)$ \\
\hline Condom / IUD & $7(14 \%)$ \\
\hline None & $20(20 \%)$ \\
\hline \multicolumn{2}{|l|}{ Alcohol intake } \\
\hline No & $28(56 \%)$ \\
\hline \multicolumn{2}{|l|}{ Soft drink intake } \\
\hline No & $13(26 \%)$ \\
\hline \multicolumn{2}{|l|}{ Coffee intake } \\
\hline No & $20(40 \%)$ \\
\hline \multicolumn{2}{|l|}{ Smoking } \\
\hline No & $50(100 \%)$ \\
\hline \multicolumn{2}{|l|}{ Nowadays you spend more time } \\
\hline Sitting & $37(74 \%)$ \\
\hline Standing & $13(26 \%)$ \\
\hline
\end{tabular}

The mean lumbar lordosis angle was $65.4^{\circ} \pm 10.9^{\circ}$, and it ranged from $37^{\circ}$ to $89^{\circ}$. The normal lordosis group ( $\mathrm{n}=$ 33) had a mean angle of $65.4^{\circ} \pm 10.9^{\circ}$; the hypolordosis group $(n=10)$ presented an angle smaller than $54.4^{\circ}$, and the hyperlordosis group $(\mathrm{n}=7)$ presented an angle greater than $76.4^{\circ}$. Among the three groups, there were no differences in the areas under study, degree of cellulite, and lumbar lordosis angle (Table 3).

The correlation data between the degree of cellulite and the angle of lumbar lordosis are presented in Table 4.

For groups having hyperlordosis, normal lordosis, and hypolordosis, Table 5 presents the correlation data between the mode of the degree of cellulite, calculated from the different areas (RSB, LSB, RIB, LIB, RST, LST), and the angle of lumbar lordosis.

\section{DISCUSSION}

The purposes of this study were to compare groups with different degrees of cellulite and different angles of lumbar
Table 3 - Mean lumbar lordosis angle. Standard deviation and $\mathrm{p}$ values obtained using ANOVA according to the assessed area and the degree of cellulite

\begin{tabular}{|c|c|c|c|c|c|c|}
\hline \multirow{2}{*}{$\begin{array}{l}\text { Cellulite } \\
\text { Area }\end{array}$} & \multicolumn{6}{|c|}{ Lumbar lordosis angle } \\
\hline & Degree & $\begin{array}{c}\text { Mean } \pm \\
\text { standard } \\
\text { deviation }\end{array}$ & Minimum & Maximum & $\begin{array}{c}\text { Sample } \\
\text { Size }\end{array}$ & $\mathrm{p}$ value \\
\hline RSB & 2 & $\begin{array}{c}66.42 \pm \\
11.05\end{array}$ & 37 & 89 & 42 & 0.414 \\
\hline RSB & 3 & $62.5 \pm 9.55$ & 49.5 & 71.5 & 6 & \\
\hline RIB & 2 & $\begin{array}{c}64.48 \pm \\
9.66\end{array}$ & 52.5 & 89 & 22 & 0.423 \\
\hline RIB & 3 & $\begin{array}{c}66.98 \pm \\
11.63\end{array}$ & 37 & 87.5 & 27 & \\
\hline RST & 2 & $\begin{array}{c}63.75 \pm \\
9.39\end{array}$ & 50 & 84.5 & 16 & 0.345 \\
\hline RST & 3 & $\begin{array}{c}66.88 \pm \\
11.35\end{array}$ & 37 & 89 & 33 & \\
\hline LSB & 2 & $\begin{array}{c}66.61 \pm \\
11.11\end{array}$ & 37 & 89 & 41 & 0.297 \\
\hline LSB & 3 & $\begin{array}{c}61.93 \pm \\
8.85\end{array}$ & 49.5 & 71.5 & 7 & \\
\hline LIB & 2 & $\begin{array}{c}63.86 \pm \\
10.39\end{array}$ & 50 & 89 & 21 & 0.264 \\
\hline LIB & 3 & $\begin{array}{c}67.36 \pm \\
10.97\end{array}$ & 37 & 87.5 & 28 & \\
\hline LST & 2 & $\begin{array}{c}63.75 \pm \\
9.39\end{array}$ & 50 & 84.5 & 16 & 0.345 \\
\hline LST & 3 & $\begin{array}{c}66.88 \pm \\
11.35\end{array}$ & 37 & 89 & 33 & \\
\hline
\end{tabular}

Table 4 - Spearman's correlation ( $r$ ) and $p$ value for the degree of cellulite and the lumbar lordosis angle

\begin{tabular}{lcc}
\hline Lumbar lordosis angle & Correlation $(\mathrm{r})$ & $\mathrm{p}$ value \\
\hline Cellulite RSB & 0.019 & 0.894 \\
Cellulite RIB & 0.204 & 0.155 \\
Cellulite RST & 0.231 & 0.106 \\
Cellulite LSB & 0.013 & 0.930 \\
Cellulite LIB & 0.246 & 0.085 \\
Cellulite LST & 0.231 & 0.106 \\
\hline
\end{tabular}

Table 5 - Spearman's correlation ( $r$ ) and $p$ value for the mode of the degree of cellulite and the lumbar lordosis angle in groups showing hypolordosis, normal lordosis, and hyperlordosis

\begin{tabular}{lcc}
\hline Groups & Correlation $(\mathrm{r})$ & $\mathrm{p}$ value \\
\hline Hypolordosis & -0.29 & 0.415 \\
Normal lordosis & 0.03 & 0.073 \\
Hyperlordosis & -0.63 & 0.122 \\
\hline
\end{tabular}


lordosis and to analyze the correlation between degree of cellulite and lumbar lordosis angle measured using Cobb's method.

Though some authors have pointed to hyperlordosis as a factor influencing the appearance of cellulite, ${ }^{14}$ the same was not observed in this study, and this discrepancy can be explained due to the different evaluations of posture used by different authors.

The physiotherapeutic postural evaluation was carried out based on the model described by Kendall et al. ${ }^{28}$ and this approach takes into account the qualitative and segmental aspects that lead to subjective data. The Kendall model was chosen because it was validated by Penha et al. ${ }^{29}$ and Griegel-Morris et al. ${ }^{30}$

During the postural assessment, the outlines of the backs and buttocks were considered instead of the traditional bone landmarks; even so, a greater gluteal prominence could be misleading and cause a false diagnosis of lumbar hyperlordosis.

Mosner et al..$^{31}$ studied the difference between black and white women's lumbar lordosis using X-rays to measure apparent lordosis based on gluteal prominence. They found that the phenotype could interfere with the methods used to evaluate lumbar lordosis. They also concluded that there was no real difference between groups despite the persistent clinical perception of greater lumbar lordosis in black women. Chen $^{22}$ affirmed that appropriate measurement of lumbar lordosis angle was important for correct clinical decisionmaking. Consistent with this recommendation, Leroux et al. ${ }^{32}$ concluded that lordosis quantification has become an important component of patients' evaluation and followup. Bernhardt and Bridwell, ${ }^{24}$ however, said that the angle for normal lumbar lordosis was less defined than the angle for normal thoracic kyphosis. According to Worrill and Peterson ${ }^{33}$ the measures for lumbar lordosis have not yet been standardized, and several authors have been using different anatomical landmarks and patient positions during evaluation, making comparisons among different studies difficult.

Jackson and McManus ${ }^{34}$ attested that an important source of lordosis exists in the L5-S1 region, and that two-thirds of L1-S1 lordosis was distributed below L4. In a study by Polly et al., ${ }^{26}$ measuring the interval between T12-S1 showed better intra-observer reproducibility. Thus, in considering total lumbar lordosis, some authors have used the inferior endplate of T12 and the superior endplate of S1 to measure Cobb's angle. ${ }^{23,25}$

The mean lumbar lordosis angle observed in this study $\left(65.4^{\circ}\right)$ was close to the values observed by other authors ${ }^{21,23,25}$ using different populations. These authors examined individuals of both sexes and of age varying from 10 to 18 years, ${ }^{23} 20$ to 63 years ${ }^{21}$ or above $40 .{ }^{25}$ Our mean lumbar lordosis angle was higher than the one reported by Harrison et al..$^{20}\left(58.6^{\circ}\right)$, who assessed a group of 30 individuals without taking age into consideration.

Correlation between cellulite and lumbar lordosis could be explained by the fact that cellulite is caused not only by the peculiarities of the female subcutaneous tissue, $2,5,7,10,11$ but also by mechanical or orthostatic alterations ${ }^{14}$ that in turn could generate circulatory alterations. ${ }^{6,7,8,20}$ However, Querleux et al. ${ }^{11}$ performed magnetic resonance imaging of the subcutaneous adipose tissue and proton spectroscopy, and found that their results did not support the hypothesis that the water contained in the subcutaneous tissue is the cause of cellulite, as suggested by some authors. ${ }^{5,9}$ This hypothesis may still be valid if the excess water in the patients of the Querleux study was located in the connective septae, since their measurements were limited to the fat lobules and did not differ between women with or without cellulite.

Terranova et al. ${ }^{7}$ emphasized the great plasticity of the adipose tissue, which would not passively suffer the consequences of microcirculatory dysfunctions proposed by the hypothesis that cellulite is caused by subcutaneous water content. The idea that adipose tissue is simply a passive reservoir of energy is no longer valid, since it is now viewed as a complex and active metabolic and endocrine organ..$^{35}$ Terranova et al. ${ }^{7}$ suggest that the capacities of this tissue recognized nowadays may influence the physiopathology of cellulite, and this influence should be examined.

One limitation of this study is the lack of women with degree 1 and degree 4 cellulite; this presumably reflects the fact that most such woman fall outside the age range of our cohort (18-35 years). Another limitation of this work is that cellulite is a multifactorial condition, which makes it impossible to eliminate intervening variables. Nevertheless, this is the first study to our knowledge that focuses not on the histopathological aspects of cellulite, but on its relationship to postural changes. Thus, the findings described here are relevant to aesthetic physical therapy.

According to Smalls et al., ${ }^{2}$ cellulite is a complex condition that requires further studies in order to explore additional factors that may influence and modulate the severity of the clinical aspects of cellulite.

\section{CONCLUSION}

This study found no correlation between lumbar lordosis angle and degree of cellulite in asymptomatic adult women. However, it is important to consider the method used to perform the postural assessment, so that consistent quantitative data can be obtained that are free from artifacts due to variations in different investigators' postural evaluations. Therefore, further studies with larger 
samples and more quantitative data are needed to confirm or refute an association between musculoskeletal alterations and cellulite.

\section{ACKNOWLEDGMENT}

The authors are grateful for financial support from Capes (Social Demands Scholarship).

\section{REFERENCES}

1. Rawlings AV. Cellulite and its treatment - Review article. Int J Cosmet Sci. 2006;28:175-90

2. Smalls LK, Hicks M, Passaretti D, Gersin K, Kitzmiller WJ, Bakhsh A. Effect of weight loss on cellulite: Gynoid Lipodystrophy. Plast Reconstr Surg. 2006;118:510-6.

3. Draelos ZD. The disease of cellulite. J Cosm Dermatol. 2005;4:221 2 .

4. Piérard GE. Commentary on cellulite: skin mechanobiology and the waist-to-hip radio. J Cosm Dermatol. 2005;4:151-2.

5. Avram MM. Cellulite: a review of its physiology and treatment. J Cosmet Laser Ther. 2005;7:1-5.

6. Rao J, Glod MH, Goldman MP. A two-center, double-blinded, randomized trial testing the tolerability and efficacy of a novel therapeutic agent for cellulite reduction. J Cosm Dermatol. 2005;4:93102 .

7. Terranova F, Berardesca E, Maibach H. Cellulite: nature and aetiopathogenesis - Review Article. Int J Cosmet Sci. 2006;28:15767.

8. Rossi ABR, Vergnanini AL. Cellulite: a rewiew. J. Eur. Acad. Dermatol. Venereol. 2000;14:251-62.

9. Sánchez CF, Tropper UP, Barceló R, Pace F, Nasi A, Brandolino C, et al. Estudos anatomopatológico e termográfico da celulite. Rev Cosmiat Med Estet. $19941^{\circ}$ trimestre. 1(II):3-13.

10. Quatresooz P, Xhauflaire-Uhoda E, Piérard-Franchimont C, Piérard GE Cellulite histopathology and related mechanobiology. Int J Cosmet Sci. 2006;28:207-10.

11. Querleux B, Cornillon C, Jolivet O, Bittoun J. Anatomy and physiology of subcutaneous adipose tissue by in vivo magnetic resonance imaging and spectroscopy: Relationships with sex and presence of cellulite. Skin Res Technol. 2002;8:118-24

12. Mirrashed F, Sharp JC, Krause V, Morgan J, Tomanek B. Pilot study of dermal and subcutaneous fat structures by MRI in individuals who differ in gender, BMI, and cellulite grading. Skin Res Technol. 2004;10:1618 .

13. Fink JS, Mermelstein H, Thomas A, Trow R. Use of intese pulsed light and a retinyl-based cream as a potential treatment for cellulite: a pilot study. J Cosm Dermatol. 2006;5:254-62.

14. Sandoval B. Fibroedema gelóide subcutáneo: qué conocemos de esta entidad clínica? Folia Dermatol. 2003;14:38-42.

15. Milani GB, Amado-João SM, Farah EA. Fundamentos da Fisioterapia dermato-funcional: revisão de literatura. Fisioterapia e Pesquisa. 2006;13:37-43

16. Craig CL, Marshall AL, Sjöstrom M, Bauman AE, Booth ML, Ainsworth $\mathrm{BE}$ et al. International physical activity questionnaire: 12-contry reliability and validity. Med Sci Sports Exerc. 2003;35:1381-95.

17. Singh D. Adaptive significance of female physical attractiveness: role of waist-to-hip ratio. J Pers Soc Psychol. 1993;65:295-307.

18. Gherardini G, Matarasso A, Serure AS, Toledo LS, DiBernardo BE. Standardization in photography for Body Contour Surgery and SuctionAssisted Lipectomy. Plast Reconstr Surg. 1997;100:227-37.
19. International Products \& Service. Interpreting the thermograms [folder]. Milano Italy; 2004.

20. Harrison DE, Harrison DD, Cailliet R, JanicTJ, Holland B. Radiographic analysis of lumbar lordosis: Centroid, Cobb, TRALL, and Harrison Posterior Tangent methods. Spine. 2001;26:E235-42.

21. Jackson RP, Hales C. Congruent spinopelvic alignment on standing lateral radiographs of adult volunteers. Spine 2000;25:2808-15.

22. Chen YL. Vertebral Centroid Measurement of lumbar lordosis compared with the Cobb Technique. Spine. 1999;24:1786-90.

23. Vedantam R, Lenke LG, Keeney JA, Bridwell K. Comparison of standing sagittal spinal alignment in asymptomatic adolescents and adults. Spine. 1998;23:211-15.

24. Bernhardt M, Bridwell KH. Segmental analysis of the sagittal plane alignment of the normal thoracic and lumbar spines and thoracolumbar junction. Spine. 1989;14:717-21.

25. Gelb DE, Lenke LG, Bridwell KH, Blanke K, McEnery KW. An analysis of sagittal spinal alignment in 100 asymptomatic middle and older aged volunteers. Spine 1995;20:1351-8.

26. Polly DWJr, KilkellyFX, McHale KA, Asplund LM, Mulligan M, Chang AS. Measurement of lumbar lordosis: evaluation of intraobserver, interobserver, and technique variability. Spine. 1996;21:1530-5.

27. Fernand R, Fox DE. Evaluation of lumbar lordosis. A prospective and retrospective study. Spine. 1985;10:799-803.

28. Kedall FP, Mc creary EK, Provance PG. Muscles, testing and function: with posture and pain. $4^{\text {th }}$ edition. Baltimore, Md, Willians \&Wilkins;1993:xv, 451.

29. Penha PJ, João SMA, Casarotto RA, Amino CJ, Penteado DC. Postural assessment of girls between 7 and 10 years of age. Clinics. 2005;60:916.

30. Griegel-Morris P, Larson K, Mueller-Klauss K, Oatis CA. Incidence of common postural abnormalities in the cervical, shoulder and thoracic regions and their association with pain in two age groups of healthy subjects. Phys Ther. 1992;72:425-31.

31. Mosner EA, Bryan JN, Stull MA, Shippee R. A comparison of actual and apparent lumbar lordosis in black and white adult females. Spine. $1989 ; 14: 310-14$

32. Leroux MA, Zabjek K, Simard G, Badeaux J, Coillard C, Rivard CH A noninvasive anthropometric technique for measuring kyphosis and lordosis. In application of idiopathic scoliosis. Spine. 2000;25:168994

33. Worril NA, Peterson CK. Effect of anterior wedging of L1 on the measurement of lumbar lordosis:Comparison of two roentgenological methods. J Manipulative Physiol Ther. 1997;20:459-67.

34. Jackson RP, McManus AC. Radiographic analysis of sagittal plane alignment and balance in standing volunteers and patients with low back pain matched for age, sex and size. A prospective controlled clinical study. Spine. 1994;19:1611-8.

35. Kershaw EE, Flier JS. Adipose tissue as an endocrine organ. J Clin Endocrinol Metab. 2004;89:2548-56. 